\title{
REGIONAL CHARACTERISTICS AND DEVELOPMENT POSSIBILITIES FOCUSING ON ENVIRONMENTAL ISSUES IN THE SERBIAN-HUNGARIAN CROSS-BORDER REGION
}

\author{
ANDRÁS DONÁT KOVÁCS \\ „Alföld” Institute, Centre for Regional Studies Hungarian Academy of Sciences \\ 6000 Kecskemét, Rákóczi u. 3. P.O. Box 261. Hungary \\ e-mail: kovacsa@rkk.hu
}

\begin{abstract}
Nowadays, the Serbian-Hungarian cross-border region can be described as presenting complex and serious settlement-environmental problems. The negative processes accelerated in the last decade causing many environmental, economic and social conflicts. After all, we think that this cross-border region will have a better future in the twenty-first century. Under the aegis of the IPA INNOAXIS project, we carried out a spatial research in this region covering three districts in Serbia (in Vojvodina autonomus province) and eight microregions in Hungary. The aim of the project was to discover the features and the development alternatives of this crossborder area. In this study we try to summarise the main characteristics and the most important strategic issues in the region from the environmental aspects.
\end{abstract}

Keywords: Serbian-Hungarian cross-border region, natural values, environmental problems, - partnership, - strategy,

\section{INTRODUCTION}

The fate of the neighbouring regions situated along state borders and the quality of life of the local communities living there are essentially affected by the character of the border. Where the co-operation between the regions and settlements located on the sides of the border is good, "border regions" can be formed with numerous opportunities; for example, through strengthening the commercial, infrastructural and cultural relations, or with respect to the exchange of information and labour force, or just the same with environmental protection, nature conservation and joint regional and settlement development. The "connecting borders" may mean a new quality and may offer several special opportunities for joint developments (Süli-Zakar, 2010). Many authors claim that the most important driver of euroregionalism is provided by cross-border co-operation initiatives. Indeed, where the borders become more open, local development may rely on cross-border regional co-operations, whereas when the dividing character of borders persists the peripheral character 
remains predominant (Krätke, 1999; Havlíček, Chromý, 2001; O’Dowd, 2001; Anderson et.al. 2003; Ladysz, 2006; Newman, 2006).

In our days, there are several border regions all over Europe where a higher level of regional cooperation can be detected; thus, these regions are no longer only economic-trading zones but reached the level of wide-scale environmental-social-economic integration (Williams, 2007). The EGTCs (European Grouping of Territorial Cooperation) are intended to achieve such kind of comprehensive integration within the European Union (EU). The EGTCs, due to the relatively flexible financial and institutional structures, develop very well functioning programme-oriented partnerships, and thus in fact may be regarded as "functional regions". The functioning of the EGTCs may be prospective in the field of cross-border co-operations. However, so far they can be operated only on areas located on the EU territory and the establishment of such organisations is not yet possible along the borders between EU member states and non member states (the countries along the external borders of the EU which are likely to become EU members in the medium term - thus including Serbia as well - form a special group where the IPA (Instrument for Pre-Accession Assistance) provides support for the co-operations along the borders).

We think that the conditions of the Serbian-Hungarian border would demand the formation of a well organised integrative structure similar to the EGTC, since one of the most important criteria in this border region is the presence, preparedness and power of the flexible institutional system.

The final goal of the regional studies conducted in the above named border zone is that through the alleviation of the dividing role of state borders and through the strengthening of the cross-border concentration the peripheral situation of the region shall cease, and the quality of life of the local communities shall improve. In the field of partnership, the advantages resulting from the geographical location of the border region and upgrading landscape resources and environmental co-operations and developments serving sustainability will presumably get a determining role. Focusing on these aspects, our study - in addition to the description of the region concerned and its most conspicuous environmental conditions - attempts to highlight possible environmental-conscious cross-border co-operation alternatives.

\section{METHODS AND OUTPUTS IN BRIEF}

The primary objective of the researches carried out in the Serbian-Hungarian border region within the framework of the IPA INNOAXIS "The borderline as an axis of innovation" (http://www. innoaxis.hu/) project was the exploration of the specific features of the region and of the development opportunities which may be built on them. This work comprised of the collection, survey and processing of the regional data and background documents necessary for the analysis, and the conduction of interviews with the prominent persons concerned. Eight different sectoral research reports were prepared based on the collected information, including the environmental sectoral document which contains situation evaluations, analyses and recommendations. Throughout the survey, the professional recommendations were harmonised with the social actors of the region, then the decision-makers in Vojvodina and in Hungary (provincial, county, microregional leaders, mayors, leaders of local communities, local development groups, and civil sphere) discussed the prepared outlines with the authors in details. After all this, the main concluding documents of the cross-border regional research project were prepared as a synthesis of the existing materials (and also on the basis of the environmental sectoral strategy). 


\section{THE SERBIAN-HUNGARIAN CROSS-BORDER REGION AND ITS ENVIRONIMENTAL STATUS}

The regions lying along the Serbian-Hungarian border are coherent from the aspect of the landscape and the environment, in fact there is no natural borderline running between the two countries (Figure 1). The region occupies a peculiar geographical position between the River Danube and River Tisza which has been divided by the present border for almost a century now.

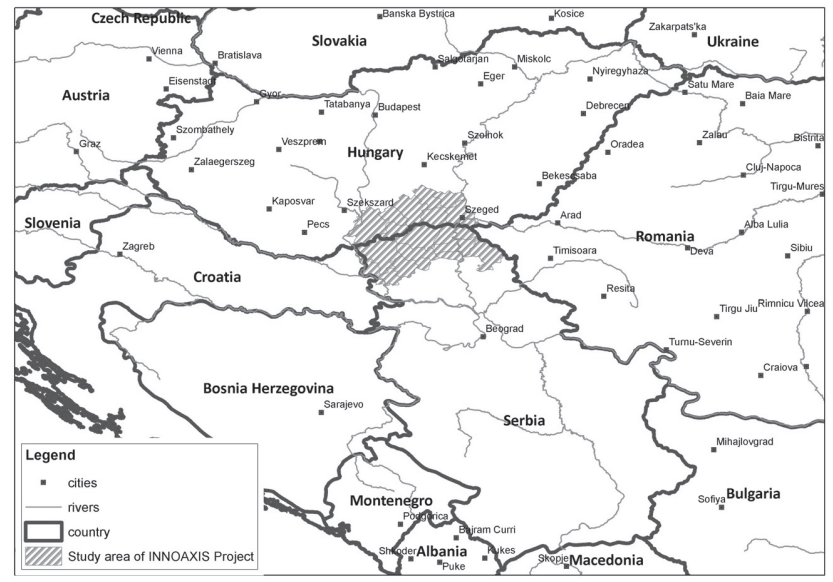

Figure 1. The examined area of the Serbian-Hungarian cross-border region Source: Great Plain Institute CRS HAS 2011

The spatial structure, due to the still strong dividing role of the border is rather split. The settlement complexes formed in the environs of Szeged, Szabadka, Zombor, Baja and Zenta constitute relatively developed poles of the region (the weight of Szeged is outstanding) but further away from the gravitation zones there are lagging behind rural areas (Figure 2).

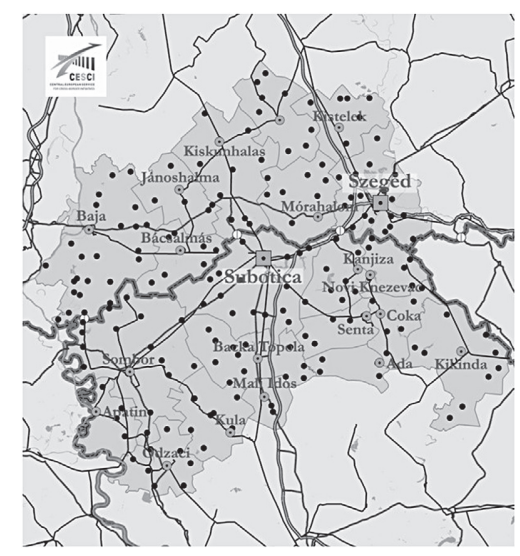

Figure 2. Spatial structure and the towns Source: CESCI 2011 
The image of the region is defined by pusztas, meadows, wetland habitats, forests and agricultural areas. Despite of the lowland features, the area is diverse and rich in natural resources whose ecosystems include the sand pusztas, loess ridges and alluvial plains. The determining elements of the natural environment of the region are the Danube, the Tisza and their tributaries and backwaters, and the protected areas which also include nature conservation areas of international importance (Figure 3). These, on the one hand, provide opportunity for creating green corridor systems; and on the other hand, also represent a recreational potential. In this respect, the harmonisation of the development of the linear infrastructural networks and of the natural environment - within it in particular the patterns of the traffic routes and the green corridors, and the protected natural values in the landscape - means a great challenge especially along the River Danube.

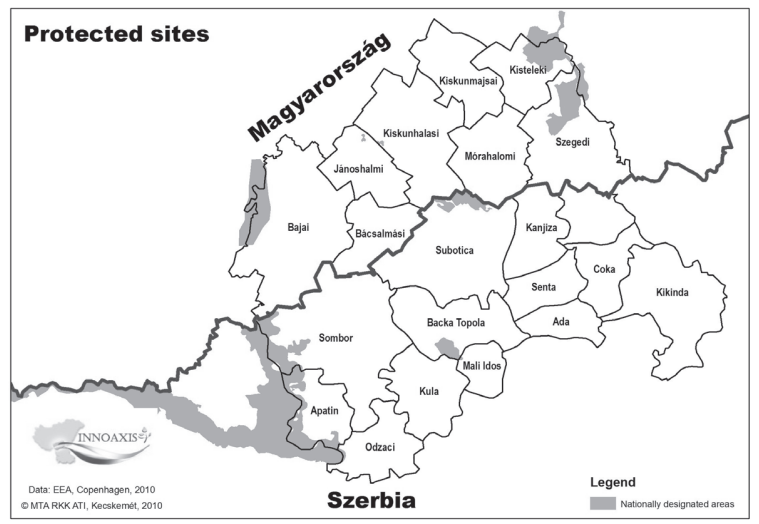

Figure 3. Protected sites

Source: Great Plain Institute CRS HAS 2011

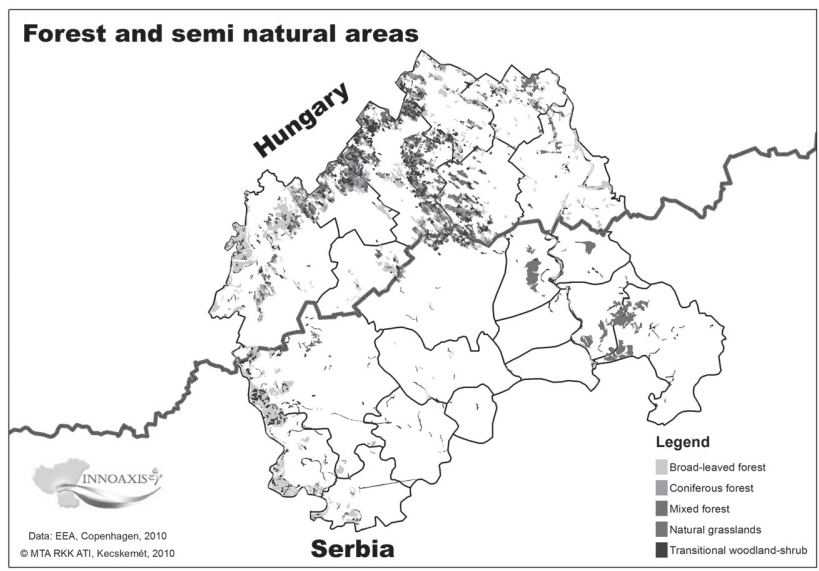

Figure 4. Semi-natural patches of the cross-border area Source: Great Plain Institute CRS HAS 2011

The former natural vegetation cover can be studied only in smaller patches on the area of the region because the intensive land use turned the original environment into cultural landscapes. In the past period it caused a problem that the clearing of the forest patches, alleys and forest belts resulted 
in the fragmentation of the ecological corridors. This intensified the vulnerability of the separated symbioses, and resulted in large-scale landscape homogenisation and degradation due to the aridity and inappropriate land use. The landscape preserved its equilibrium state only in some semi-natural patches (Figure 4).

The area is characterised by continental climate, and regarding the precipitation the region concerned belongs to the dryer regions of the Carpathian Basin, and we may even experience a microclimate tending to drought. The unfavourable ecological changes related to the aridity characterising the region, and the negative economic and social tendencies partly caused by it may injuriously influence the competitiveness of the entire region (Table 1).

Table 1. The complex settlement-environmental problems of the Serbian-Hungarian cross-border region

\begin{tabular}{|l|}
\hline \multicolumn{1}{|c|}{ Natural-environmental problems } \\
\hline - growing extremity of the climate, uneven precipitation supply \\
\hline - the groundwater is deep under the surface \\
\hline - degradation of soils \\
\hline - homogenisation of landscapes \\
\hline - unregulated architecture not merging into the landscape and wasteful environmental use \\
\hline - ecological degradation \\
\hline - negative symptoms of the rural society - deprivation, unemployment, ageing, out-migration, social \\
exclusion \\
\hline - cumulative social stress - poverty, criminality, "segregation" \\
\hline - a significant decrease in the dominancy of agriculture, the uncertainty of agricultural production \\
\hline - the "collapse" of the relationship between towns and villages, conflicts of urban and rural lifestyle \\
\hline - slow infrastructural development \\
\hline - the lagging behind and powerlessness of the environmental management and planning - the missing plans \\
of territorial development
\end{tabular}

Source: own elaboration (2011)

On the whole, the chief potential of the studied region still resides in its existing environmental resources. From among the "rural-environmental" resources encountered here the ecological and agro-cultural landscape conditions are the most important. In addition to them, however, we should increasingly consider the unfavourable factors. Though, the border zone under consideration does not belong to the group of environmentally dangerously damaged regions but some of its parts were not avoided by the pollutions and damages resulting from the ill-considered land use. In the region, the process of urbanisation was not - or only in a very varying way depending on the area - followed by the development of those infrastructures which serve the mitigation or prevention of the loading and damage of the settlement environment. In many points, especially in the case of the Serbian settlements, the classic environmental prevention and protection measures and investments were missing. Huge regional differences developed in almost all fields of environmental activities, and thus today the environmental management of the settlements (including waste management) is significantly below the European standard. In principle, the regions on the Hungarian side - applying EU environmental rules - are in a better position but the situation of the individual microregions on the Hungarian side differs. 
One of the most important recognitions of the past period is that most of the conflicts of the region may not be linked only to the economic problems but also to the social behaviour lacking and neglecting the appropriate environmental knowledge and approach, and to errors and deficiencies in environmental management experienced on the professional and decision-making levels.

\section{THE MOST IMPORTANT STRATEGIC ISSUES}

The development of a regional environmental management system which can be harmonised with the help of the co-operations in the Serbian-Hungarian border region became extremely urgent. The extension of the co-operations is an important task on most of the sectors of environmental protection; both in relation to the establishment of the nature conservation, common environmental and water management objectives, and the strengthening of the human background of environmental protection.

In the course of the joint protection of the natural environment, the acquaintance with the best practices already applied in the EU and the elaboration of cross-border landscape and environmental management and drinking water protection strategies are necessary. The elaboration of the crossborder waste management strategy and the transfer of the best practice from a Hungarian side to the Serbian local governments may be high priority objectives. For the sake of this, it must be examined on the regional and local government level on which areas the joint waste collection public service development could be implemented, and where and under what circumstances the waste collection and disposal habits of the population concerned could be improved.

The creation of the partnership is also of considerable importance in the settlement of the water management of the region. For the flood events of the past decade called attention to the fact that new and reconsidered actions are needed to increase flood safety in the border region both for the Danube and the Tisza. Although, the tasks related to water management - in particular flood mitigation - are not really regional environmental tasks because of their international strategic significance but they have regional as well as local aspects and tasks. The achievement of flood safety, the optimising of water management of the areas affected by aridity, in addition to the protection of surface waters and the rehabilitation of backwaters and canals, the technical inspection of the flood defence-works and networks of canals, the modernisation of the objects concerned constitute a complex scope of duties related to landscape management, agriculture, spatial planning and environmental awareness raising in the region. The joint water management requires the harmonisation of the agri-environmental objectives in many respects. For instance, land use transformation, the rehabilitation of the ecological and water system of the floodplains and the drafting of joint landscape management programmes should be encouraged on the low flood plains suitable for floodplain landscape management.

The environmental state of a region mostly depends on how the communities living on the area approach the landscape and the settlement environment. The environmentally more balanced development implies environmental consciousness; that is, an environmentally friendly social approach and attitude. In this respect, the spread of local environmentally friendly forms of production, consumption patterns and alternative environmental technologies should be encouraged, the producers as well as the social communities should be motivated to fully respect the gradually tightening environmental norms, and to rational and efficient management of the less and less resources. This requires continuous learning and spread of the environmental approach in the local social communities. It is particularly important for the microregions along the border and for the Serbian villages to make environmental consciousness the aspect of long-term sustainability. Therefore, one of the most 
important priorities of the environmental strategy focuses on raising the environmental awareness of the people (Tab. 2). Environmental education must be developed on all levels of public education, it should be achieved that environmental consciousness becomes part of the general knowledge. It must be brought to consciousness that the improvement of the environmental conditions is not the honouring of an obligation serving external interests but the direct condition of the improvement of personal welfare. Those eco-schools are especially appropriate for this purpose which incorporate the environmental knowledge into their basic training in accordance with the local conditions, and transfer the "green approach" through a systematically built curriculum from the early school years. There are excellent examples in Hungary whose many years' experiences could be also applied in the schools of Vojvodina.

2. Table 2. Priorities of the environmental strategy in the Serbian-Hungarian cross-border region

I. Co-operations for the protection of natural resources and for modern waste management (alignment with drinking water protection and waste management)

II. Establishment and renewal of co-operations in water management

III. Intensification of environment-consciousness, transfer of educational training methods in awareness raising for the Serbian settlements - knowhow transfer, expansion of background information

IV. Use of alternative energy - dissemination of the use of renewable energy sources, encouragement of the use of environmentally friendly "clean" production and heating technologies with the help of joint investments

V. Promotion of sustainable landscape management and providing attractive recreational and eco-management environment in the studied border region

VI. Development of a more liveable settlement environment

Source: by own elaboration (2011)

It should be emphasised that the above named developments may be implemented only in the case of a scenario in which the harmonisation of the environmental acts based on the agreement of the countries is achieved in the future, the EU environmental principles are adopted, the EU case-law is introduced and the environmental regulatory prescriptions are kept and given effect in Serbia.

\section{SUMMARY}

The creation of the modern environmental management and the provision of the regional equilibrium in environmental quality are important components in the development of the Serbian-Hungarian cross-border region. As a consequence of the earlier EU accession of Hungary, today considerable differences may be perceived on the two sides of the border regarding the state of the environment. While the environmental-conscious transformation of the formerly most critical sectors (for example, waste management, wastewater management, drinking water supply) in the eight microregions on the Hungarian side significantly accelerated during the past decade (and with the Natura 2000 Networking Programme the situation of nature conservation has also significantly changed), in the case of the villages in Vojvodina the environmental actions in these fields progressed only very slowly in the past few years and the environmental-infrastructural developments are still missing.

The common development of the natural, man-made and the social, cultural-mental environment are important conditions for the regional catching up and equilibrium. The specific ecologicallandscape features of the region can be preserved in the long-term only through the emergence of 
complexly interpreted environmental actions. The border region will become an agri-environmental and ecoturistic target area only through development initiatives underlying an environmental approach, and it will keep its population only through making the settlements more liveable. From the aspect of the development of the Serbian-Hungarian cross-border region, therefore, it is a criterion of primary importance to protect the affected landscapes and settlement environment systems, and to harmonise and catch-up the environmental activities in the institutional and civil spheres. The improvement of the quality of life of the population concerned may be achieved through the creation of environmental safety in the cross-border region which means both the liveable settlement environment and the sustainable use of resources. The optimal use of the landscape conditions and settlement environment systems is an essential pledge for the prosperity of the population living and working in the border region.

\section{REFERENCES}

Anderson J., O'Dowd L., 1999, Borders, border regions and territoriality: contradictory meanings, changing significance. Regional Studies 33(7), 593-604.

Anderson J., O’Dowd L., Wilson T. M. (eds.), 2001, Cross-Border Co-operation, Special Issue of Administration 49(2).

Anderson J., O’Dowd L., Wilson T. M. (eds), 2003, New Borders for a Changing Europe: Crossborder Cooperation and Governance, London: Frank Cass.

Donnan H., Haller D. (eds), 2000, Borders and Borderlands: An Anthropological Perspective, Special Issue of Ethnologia Europea 30(2).

Havlíček T., Chromý P., 2001, Contribution to the theory of polarized development of a territory, with a special attention paid to peripheral regions. Geografie 106(1), 1-11.

Krätke S., 1999, Regional integration of fragmentation? The German-Polish border region in a new Europe. Regional Studies 33(7), 631-641.

Ladysz J., 2006, Chosen aspects of sustainable development on the Polish, Czech and German borderland. GeoJournal 67(1), 1-7.

Newman D., 2006, The lines that continue to separate us: borders in our "borderless" word. Progress in Human Geography 30(2), 143-161.

O'Dowd L., 2001, Analysing Europe's borders, IBRU Boundary and Security Bulletin Summer 2001, 67-79.

Perkmann M., 1999, Building governance institutions across European borders. Regional Studies 33(7), 657-667.

Wallace C., 1999, Crossing borders: mobility of goods, cupital and people in the central European region. In: A. Brah, M.J. Hickman, M. Ghaill (eds.), Global futures: migrations, environment and globalization. London: Macmillan, 185-209.

Williams M.B., 2007, On Europe's Edge: Changing borders in Central and Eastern Europe. Contemporary Studies in Economic and Financial Analysis 89, 137-171. 